\title{
Article \\ UV Properties and Loading into Liposomes of Quinoline Derivatives
}

\author{
Sara Battista ${ }^{1}$, Vincenzo Marsicano ${ }^{1}$, Antonio Arcadi ${ }^{1}{ }^{(0)}$, Luciano Galantini ${ }^{2, *}{ }^{\mathbb{C}}$, Massimiliano Aschi ${ }^{1}(\mathbb{D}$, \\ Elena Allegritti ${ }^{1}$, Alessandra Del Giudice ${ }^{2}$ and Luisa Giansanti ${ }^{1, *}$ (D) \\ 1 Dipartimento di Scienze Fisiche e Chimiche, Università degli Studi dell'Aquila, Via Vetoio 10, \\ 67010 Coppito (AQ), Italy; sara.battista@univaq.it (S.B.); vincenzo.marsicano@graduate.univaq.it (V.M.); \\ antonio.arcadi@univaq.it (A.A.); massimiliano.aschi@univaq.it (M.A.); \\ elena.allegritti@graduate.univaq.it (E.A.) \\ 2 Dipartimento di Chimica, Università di Roma "La Sapienza", Piazzale Aldo Moro 5, 00185 Roma, Italy; \\ alessandra.delgiudice@uniroma1.it \\ * Correspondence: luciano.galantini@uniroma1.it (L.G.); luisa.giansanti@univaq.it (L.G.)
}

\section{check for} updates

Citation: Battista, S.; Marsicano, V.; Arcadi, A.; Galantini, L.; Aschi, M.;

Allegritti, E.; Del Giudice, A.

Giansanti, L. UV Properties and

Loading into Liposomes of Quinoline Derivatives. Colloids Interfaces 2021, 5 , 28. https://doi.org/10.3390/colloids 5020028

\section{Academic Editors:}

Alexander Kamyshny and Victor Starov

Received: 1 February 2021

Accepted: 28 April 2021

Published: 7 May 2021

Publisher's Note: MDPI stays neutral with regard to jurisdictional claims in published maps and institutional affiliations.

Copyright: (c) 2021 by the authors. Licensee MDPI, Basel, Switzerland. This article is an open access article distributed under the terms and conditions of the Creative Commons Attribution (CC BY) license (https:// creativecommons.org/licenses/by/ $4.0 /)$

\begin{abstract}
The scientific relevance of quinolines is strictly linked to the fine-tuning of their features by functionalizing the heterocyclic core. Consequently, the compounds of this class are very versatile and can be used as possible drugs for a lot of medical applications. In this work, the inclusion of eight synthetic quinoline derivatives in liposomes formulated with different lipids was investigated in terms of the encapsulation efficiency and to highlight the effect on the liposome size distribution and thermotropic behavior. Excellent encapsulation was accomplished with all the quinoline/phospholipid combinations. Differences in the interactions at the molecular level, dependent on the quinoline molecular scaffolds and lipid structure, were observed, which could significantly bias the interaction with the drug and its release in pharmaceutical applications. Experiments in combination with computational studies demonstrated that the UV absorption of quinolines with expanded conjugation could be affected by the environment polarity. This was probably due to a solvent-dependent ability of these quinolines to stack into aggregates, which could also occur upon inclusion into the lipid bilayer.
\end{abstract}

Keywords: quinolines; liposomes; lipid-drug

\section{Introduction}

Quinolines are well-known compounds mostly investigated for their biological properties [1,2]. They are alkaloids both present in nature and prepared synthetically [3]. The heterocyclic nitrogen-containing skeleton is fundamental for biological activity, but the properties can be selected and improved by changing the nature of the substituents around the building block $[4,5]$. In fact, a different functionalization can confer to quinolines peculiar features such as antibacterial [6], antifungal [7], antimalarial [8], analgesic [9], antiviral [10], antineoplastic [11], anti-inflammatory [12], and neuroprotective [13] activities. Nowadays, a lot of commercial drugs contain molecules with a quinoline core. Examples are Levatinib [14], a urea derivative of quinoline used for the treatment of thyroid cancer; topotecan [15], a synthetic analogous of camptothecin used to treat ovarian, cervical, and lung tumors; chloroquine [2] used against malaria illness; and badaquiline [16] for the treatment of tuberculosis. Other applications are in the sensoristic area, for example, the recognition and the identification of different bacterial species [17] and/or the diagnosis of human pathologies exploiting the properties of synthetic florescent quinoline derivatives in the absence [18] or in the presence [19-21] of metal ions abundant in biological systems. In general, quinoline scaffolds are also investigated for their potential applications as agrochemicals and as synthetic building blocks [22]. Low solubility hampers their application, especially in the pharmacological area $[23,24]$. The inclusion of quinolines in liposomal formulations is herein proposed to overcome the solubility obstacle based on the well-known 
ability of these carriers to improve tissue uptake, bioavailability, and targeting of many compounds [25-28]. Biocompatibility, the ability to entrap both lipophilic and hydrophilic drugs, along with the possibility to modify their surface and composition make liposomes particularly versatile carriers [29]. Considerably, the tolerated drug dose is sometimes increased by its delivery in liposomes [30-32].

Here, we reported on the loading into liposomes of different quinoline derivatives with a molecular structure ranging from the slightly modified basic quinoline skeleton to remarkably substituted ones (Scheme 1) in order to investigate the effects of welldefined parameters such as the extension of conjugation and polarity, in addition to the overall complexity of the molecular skeleton. Starting from the basic aromatic structure of quinoline 4 , the degree of unsaturation was increased by adding one $(5,7,8)$ or two $(\mathbf{1}, 2,3, \mathbf{6})$ aromatic residues, including a phenacyl group in the case of $\mathbf{1}, \mathbf{2}, 3, \mathbf{6}, \mathbf{7}$, and $\mathbf{8}$, and an additional double bond (7). However, an expansion of the conjugation only occurred in 3 and 7 , where the additional unsaturation was in resonance with the basic quinoline aromatic skeleton. The insertion of carbonyl groups entailed an increase in polarity, sometimes in parallel with the introduction of fluorine atoms or ether groups (6). These changes provided a general increase in the structure complexity, which was remarkably enhanced in the steroidal quinolines $(7,8)$. This class of quinolines gained great attention, as they possess many pharmacological activities and show biological properties very sensitive to even small modifications of their chemical structure [33-35].<smiles>CC(C)(C)C1CCc2nc3ccccc3c(CC(=O)c3ccccc3)c2C1</smiles>

1<smiles>c1ccc2nc3c(cc2c1)CCC3</smiles>

4<smiles>O=C(Cc1c2c(nc3ccccc13)CCC(c1ccccc1)C2)c1ccccc1</smiles>

2<smiles>c1ccc(-c2c3c(nc4ccccc24)CCCC3)cc1</smiles>

5<smiles>O=C(Cc1c2c(nc3ccccc13)-c1ccccc1C2)c1ccccc1</smiles>

3<smiles>COc1ccccc1C(=O)Cc1c2c(nc3c(F)cc(F)cc13)CCC(c1ccccc1)C2</smiles><smiles>CC(C)CCC[C@H](C)[C@H]1CC[C@H]2[C@@H]3CC=C4c5c(nc6ccccc6c5CC(=O)c5ccccc5)CC[C@]4(C)[C@H]3CC[C@@]21C</smiles>

7<smiles>CC(C)CCC[C@H](C)[C@H]1CC[C@H]2[C@@H]3CC[C@H]4Cc5nc6ccccc6c(CC(=O)c6ccccc6)c5C[C@]4(C)[C@H]3CC[C@@]21C</smiles>

8

Scheme 1. Synthetic quinolines.

The spectroscopic behavior of the quinolines was also investigated in different solvents in order to assay their sensitivity to the environment polarity both experimentally 
and by computational methods. Quantum chemical calculations were carried out for analyzing the ground and low-lying excited states of all the investigated species. Moreover, a semi-quantitative interpretation of the experimental absorption spectra was performed, introducing the solvent effect on UV transitions. The molecules under investigation, with a few exceptions, were characterized by a relatively large internal mobility, and hence, a large number of conformations should be taken into account for a quantitative evaluation of the spectral features. In this study, we have limited our attention only to a single structure, which resulted in the lowest-energy minimum among a reduced number of species. Additional calculations with also dynamical effects are currently underway in our laboratory and will be the subject of forthcoming studies.

Quinolines 1-8 were also included in liposomes formulated with saturated or unsaturated lipids and with different chain lengths (Scheme 2) to gain information on the mutual influence of the structure of quinolines and/or of lipids on the properties of the liposome/quinoline aggregates. In fact, differences in the lipid chain length and/or in the degree of unsaturation affected the features of the aggregates they form [36,37]. Moreover, in a previous work, we observed that subtle variations of the polar headgroup and/or of the alkyl chain region of minor components of liposome formulations influenced the antibacterial activity of the active principle included in the vesicle bilayer [38].

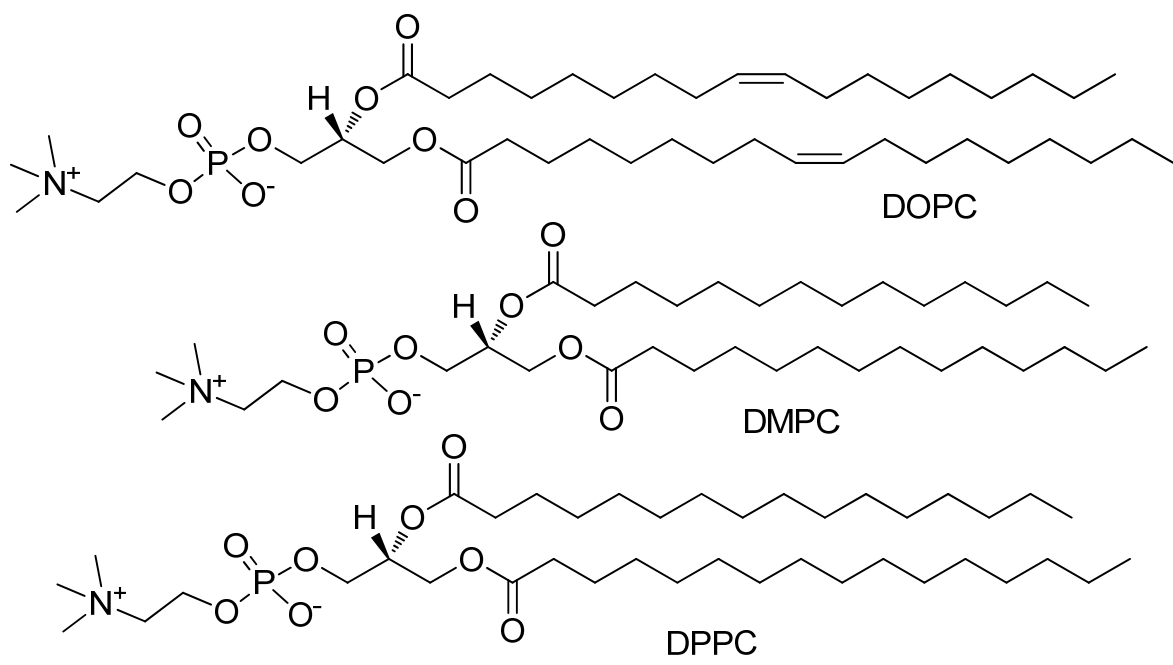

Scheme 2. Liposome components.

\section{Materials and Methods}

\subsection{Instrumentation}

Liposomes were prepared using a Hielscher UP100-H ultrasonic processor (Hielscher Ultrasonics, Teltow, Germany) with a microtip probe $(7 \mathrm{~mm})$. Dynamic light scattering (DLS) measurements were performed to infer hydrodynamic diameters of liposomes by using a Zetasizer Nano ZS (Malvern Panalytical, Malvern, UK) equipped with a $5 \mathrm{~mW} \mathrm{He}-$ Ne laser operating at $633 \mathrm{~nm}$ and combined with non-invasive backscatter technology. UV measurements were carried out in a Varian Cary $50 \mathrm{UV}$-vis double beam spectrophotometer (Agilent Technologies Inc., Santa Clara, CA, USA). Fluorescence measurements were performed on a PerkinElmer LS-50 spectrofluorometer (PerkinElmer.Inc, Waltham, MA, USA). DSC measurements were carried out using a Mettler Toledo DSC 3 calorimeter (Mettler-Toledo International Inc., Columbus, OH, USA). Small Angle X-ray Scattering (SAXS) analysis was performed at SAXSLab Sapienza with a Xeuss 2.0 Q-Xoom system (Xenocs SA, Sassenage, France), equipped with a micro-focus Genix 3D X-ray Cu source $(\lambda=0.1542 \mathrm{~nm})$, a two-dimensional Pilatus3 R 300K detector placed at a variable distance from the sample, and an additional Pilatus $3 \mathrm{R} 100 \mathrm{~K}$ detector at a fixed shorter distance from the sample to access larger scattering angles (Dectris Ltd., Baden, Switzerland). 


\subsection{Materials}

Lipids, phosphate-buffered saline tablets (PBS, $0.01 \mathrm{M}$ phosphate buffer; $0.0027 \mathrm{M} \mathrm{KCl}$; $0.137 \mathrm{M} \mathrm{NaCl} ; \mathrm{pH} 7.4$ ), dialysis tubing cellulose membrane (cut-off $=14,000$ ), and solvents were purchased from Sigma-Aldrich. The synthetic quinolines were prepared as previously described $[39,40]$. All reagents used for the synthesis and solvents were used without further purification.

\subsection{UV Characterization of Quinolines}

$\mathrm{UV}$-vis spectra for each quinoline were carried out in $n$-hexane, isopropanol, $\mathrm{CHCl}_{3}$, methanol. Stock solutions of quinolines in $\mathrm{CHCl}_{3}$ at $12.5 \mathrm{mM}$ were prepared; small aliquots of each of them were put in a cuvette, and the solvent was removed. Then the proper solvent was added to arrive at a final concentration of quinoline equal to a $1 \times 10^{-5} \mathrm{M}$ except [4] that was equal to $4 \times 10^{-5} \mathrm{M}$.

\subsection{Computational Details}

The calculations were performed in the framework of the Density Functional Theory using the hybrid functional Becke3LYP [41,42] in conjunction with the 6-31G ${ }^{*}$. The effect of other functionals was not taken into account in this study. The structures of species 1-8 were first optimized and then used for evaluating the vertical excitation energies using the Time-Dependent Density Functional Theory (TD-DFT) [43]. Note that for $\mathbf{7}$ and $\mathbf{8}$, the long alkyl chain, certainly irrelevant in the low-energy electronic transitions, was substituted with a methyl group. The solvent effect was introduced using a Polarizable Continuum Model [44] as implemented in the Gaussian 09, which was the package adopted for all the calculations [45]. The spectra were depicted using Gaussian functions centered onto the TD-DFT calculated transitions using a sigma estimated on the basis of the dispersion of the vertical transitions obtained for three different structures of species 7 and $\mathbf{8}$. Obviously, this value provided us only with a rough estimation of this parameter, which should be specifically evaluated for all the species independently, and also should include the broadening deriving from the thermal effects of the solvent. These aspects, out of the scope of this preliminary article, are currently under investigation in our laboratory. Note that we have adopted the approximation of considering the same sigma for all the species. Details of the utilized structures, as well as all the vertical transitions and the corresponding oscillator strengths, are reported in the Supplementary Information.

\subsection{Liposomes Preparation and Quinolines Inclusion}

Lipid films were prepared on the inside wall of a round-bottom flask by evaporation of solutions containing the proper amount of phospholipid (dissolved in $\mathrm{CHCl}_{3}$ ) and the appropriate quinoline at a 20:1 molar ratio. The obtained films were stored overnight under reduced pressure $(0.4 \mathrm{mbar})$, then PBS was added to obtain $3 \mathrm{~mL}$ of a $5 \mathrm{mM}$ lipid dispersion. The solutions were heated at $50{ }^{\circ} \mathrm{C}$ and vortex-mixed, then the suspensions containing multilamellar vesicles (MLV) were sonicated for $8 \mathrm{~min}$ at $72 \mathrm{~W}$ (cycles $0.5 \mathrm{~s}$ ), using a Hielscher UP100-H ultrasonic processor with microtip probe $(7 \mathrm{~mm})$. To remove unentrapped quinolines, dialysis exchanging the external medium PBS solution (25-fold the liposomes dispersion volume) 8 times in two hours was carried out. Before carrying out dialysis on liposomes containing quinolines, we tested the efficacy of the same procedure on free $0.25 \mathrm{mM}$ quinoline solutions prepared by dispersing in $3 \mathrm{~mL}$ of PBS quinolines solution in DMSO. After the dialysis was carried out according to the described procedure, we verified by UV measurements that all quinolines were removed from the dialysis bag.

\subsection{Evaluation of Entrapment Efficiency}

Entrapment efficiency (E.E.) was evaluated before and after the removal of free quinolines by UV measurements on samples obtained by adding $1.5 \mathrm{~mL}$ of methanol to $1.5 \mathrm{~mL}$ of a properly diluted liposome suspension. E.E. values were assessed by the ratio between 
the absorbance value at the maximum intensity of absorption for each quinoline before and after dialysis.

\subsection{DLS Measurements}

DLS measurements were carried out at $25^{\circ} \mathrm{C}$ on $1 \mathrm{mM}$ liposome solutions soon after their preparation, and after one and two weeks upon storage at room temperature. To obtain the size distribution, the measured autocorrelation functions were analyzed by means of the non-negative least square (NNLS) algorithm. The distribution of the diffusion coefficients $\mathrm{D}$ of the particles was converted into a distribution of apparent hydrodynamic diameters $D_{H}$ using the Stokes-Einstein relationship $D_{H}=k T / 3 \pi \eta D$, where $k T$ is the thermal energy and $\eta$ the solvent viscosity. Reported $\mathrm{D}_{\mathrm{H}}$ values and size distribution corresponded to the average values over several measurements and were obtained from intensity weighted distributions. All values reported were the average of three consecutive measurements of the same samples.

\subsection{Differential Scanning Calorimetry}

Differential scanning calorimetry (DSC) measurements were carried out on $30 \mu \mathrm{L}$ of $\operatorname{MLV}(1 \mathrm{mg} / 10 \mu \mathrm{L}, \approx 148 \mathrm{mM}$ in total lipids) prepared according to the lipid-film hydration method described in Section 2.5 in the presence and in the absence of quinolines. Two heating scans were recorded at a rate of $5{ }^{\circ} \mathrm{C} / \mathrm{min}$, and two subsequent heating scans were recorded at a rate of $1^{\circ} \mathrm{C} / \mathrm{min}$ with a pre-scan equilibration period of $10 \mathrm{~min}$ in the range $10 \div 28^{\circ} \mathrm{C}, 31 \div 44^{\circ} \mathrm{C},-25 \div-15^{\circ} \mathrm{C}$ for DMPC, DPPC, and DOPC liposomes, respectively. Under the experimental conditions, reproducible thermal recordings were obtained. Temperatures were determined with an accuracy of $\pm 0.1^{\circ} \mathrm{C}$ and $\Delta \mathrm{H}$ values with an accuracy of $\pm 0.5 \mathrm{~kJ} / \mathrm{mol}$.

\subsection{SAXS Analysis}

SAXS measurements were performed on $15 \mathrm{mM}$ liposome solutions within one week from their preparation. The samples were loaded into vacuum-tight quartz capillary cells with a thickness of $1.5 \mathrm{~mm}$ and measured in the instrument sample chamber at reduced pressure $(\sim 0.2 \mathrm{mbar})$ in a thermostated holder at $25^{\circ} \mathrm{C}$.

Measurements with different sample-detector distances were performed so that the overall explored $q$ region $\left(q=4 \pi \sin (\theta) / \lambda\right.$, where $2 \theta$ is the scattering angle) was $0.045 \mathrm{~nm}^{-1}$ $<\mathrm{q}<33 \mathrm{~nm}^{-1}$, or $0.045 \mathrm{~nm}^{-1}<\mathrm{q}<10 \mathrm{~nm}^{-1}$ when using capillary cells with a smaller opening. The two-dimensional scattering patterns were subtracted for the dark counts and then masked, azimuthally averaged, and normalized for transmitted beam intensity, exposure time, and subtended solid angle per pixel by using the FoxTrot software (version 3.4.9) developed at SOLEIL. The one-dimensional I vs. q profiles were then subtracted for the buffer and cell contributions and put in absolute scale units $\left(\mathrm{cm}^{-1}\right)$ by dividing for the known thickness. The different angular ranges were merged using the SAXSutilities tool [46].

\section{Results and Discussion}

\subsection{Quinolines Characterization}

Absorption properties of the different quinolines in different solvents and in liposomes were investigated. The obtained spectra for free quinolines are reported in Figure 1.

A systematic analysis of the electronic properties of the ground and the lowest (vertical) excited states for all the species from 1 to 8 in the gas phase was carried out with the aim of evaluating possible electronic effects provided by different substituents. The transition energies and the character of the first ten transitions, as well as the pictures of the involved molecular orbitals, are reported in Table S1 and Figures S1 and S2. The full list of the transitions, including the low-intensity ones and the corresponding oscillator strengths, are summarized in Table S2. TD-DFT calculations in the presence of an approximated model of the solvent effect were also carried out for interpreting the experimental absorption. 
The first twenty transitions obtained by calculated spectra are evaluated and depicted in Figure 2.
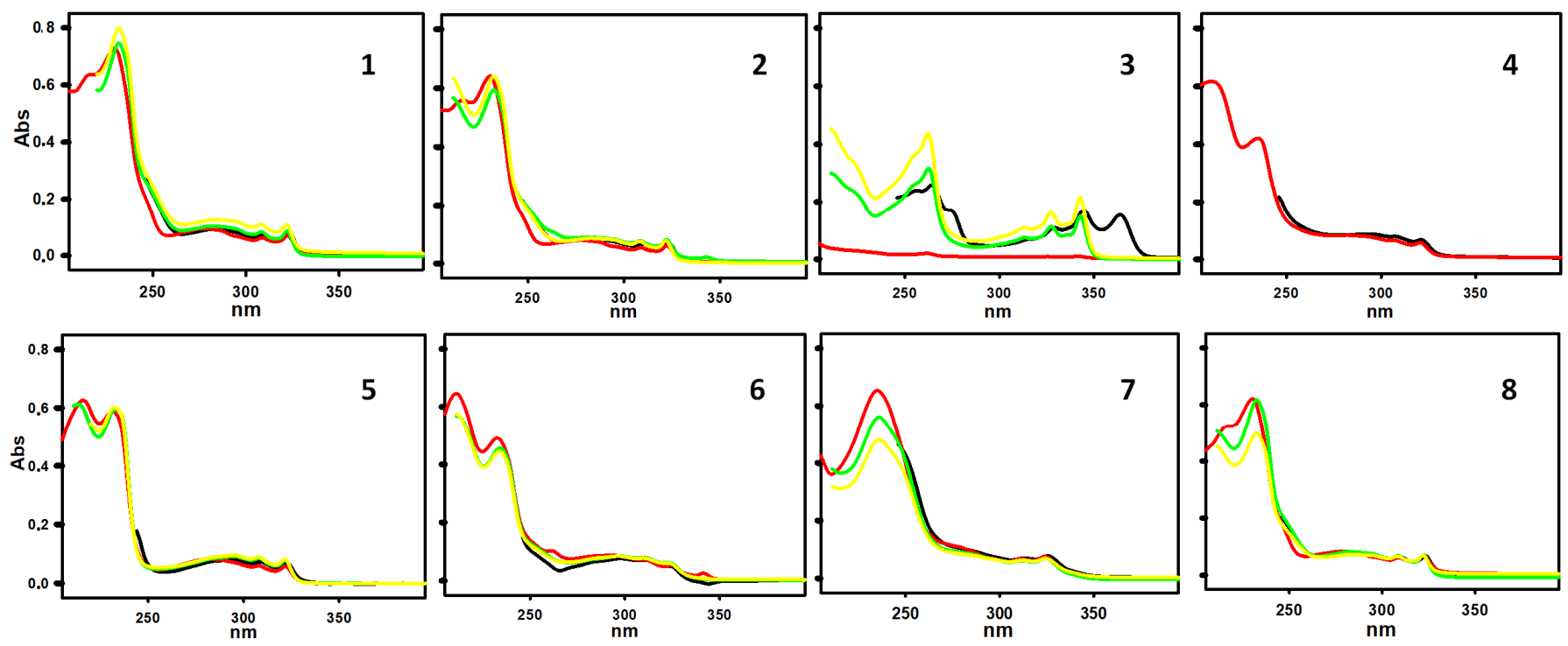

Figure 1. UV spectra of free quinolines (1-8) in $n$-hexane (red line), chloroform (black line), methanol (yellow line), and 2-propanol (green line). The concentration used for quinoline 4 is $5 \times 10^{-5} \mathrm{M}$, fivefold the concentration of the quinolines in other panels.
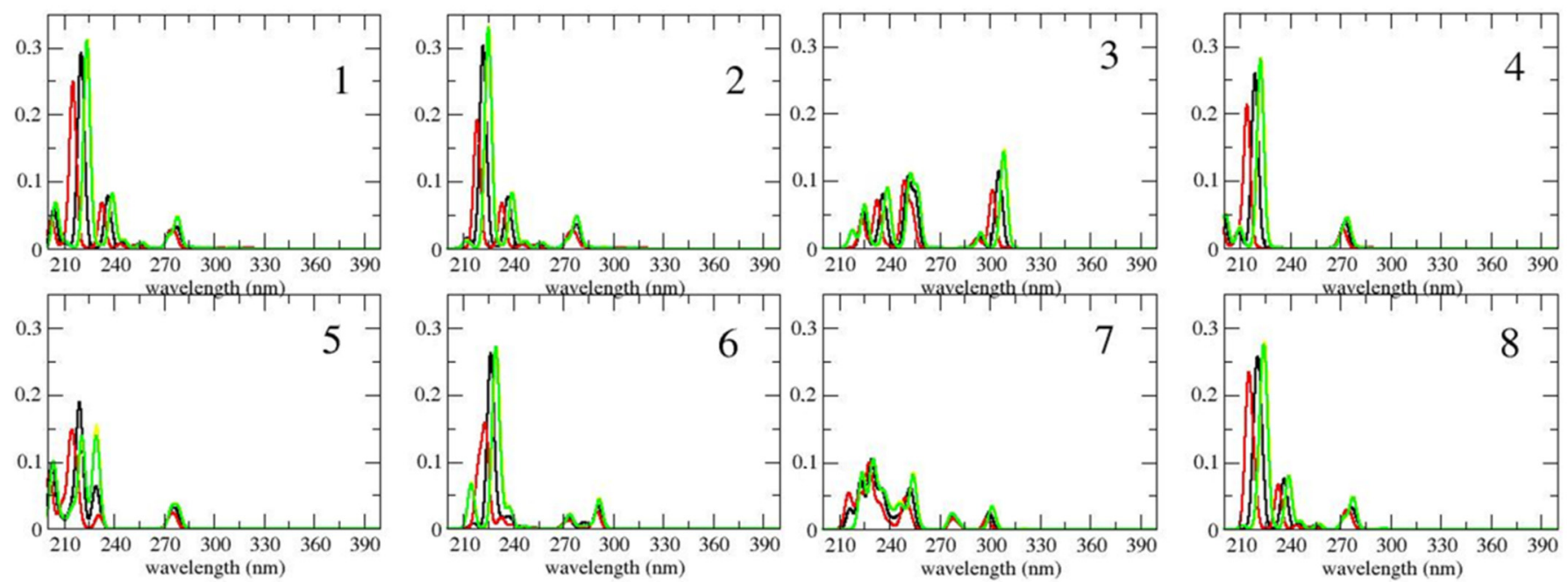

Figure 2. Collection of the calculated spectra of quinolines (1-8) in different $n$-hexane (red line), chloroform (black line), methanol (yellow line), and 2-propanol (green line). Intensities correspond to oscillator strengths reported in arbitrary units.

It is clearly observable that the experimental UV spectra did not show significant differences as a function of the solvent with the exception of quinolines 3 (Figure 1 and Figure S3), for which a sharp red-shift was observed in chloroform, and that turns out to be not sufficiently soluble in $n$-hexane for providing a detectable signal. The calculated spectra were characterized by a relatively high number of intense peaks, reasonably being the origin of the experimentally observed large and intense absorption pattern below $260 \mathrm{~nm}$. For all the species, the highest peak was essentially a $\pi-\pi^{*}$ quinoline-localized excitation accompanied by a moderately large dipole moment, essentially parallel to but slightly higher (about $20 \%$ ) than the ground state dipole moment $\mu_{0}$, well explaining the calculated red shift observed when the solvent polarity increased. Concerning the low-energy domain of the spectra (approximately from $3.5 \mathrm{eV}$ to $4.5 \mathrm{eV}$, see also Table S1), it was interesting to note that all the species containing the phenacyl group in position 4 of the quinoline ring 
(i.e., quinolines $1,2,3,7$, and 8 ) showed a very similar absorption-energy pattern because of the high resemblance of the patterns of the frontier orbitals (Figure S1). In this respect, in all of the above-mentioned species, the presence of low-energy orbitals, with a marked separation in the electron density between quinoline and phenacyl substituents, suggested that the quinoline moiety acted as an electron donor moiety upon low-energy photon absorption, producing low-lying charge transfer (CT) transitions $[47,48]$ accompanied by a moderate solvent effect related to the increase in the dipole moment with respect to $\mu_{0}$. For the other investigated quinolines, the same absorption-energy pattern turned out to be sharply blue-shifted, hence, indicating a lower tendency of the two moieties to exchange the charge. This was due either to the substitution of the phenacyl group into position 4 with an $\mathrm{H}$ or a $\mathrm{Ph}$, in 4 and 5, or to the presence of inductively electron-withdrawing groups such as the fluorine atoms in $\mathbf{6}$.

Finally, worth a remark was also the systematic presence of a signal at about $275 \mathrm{~nm}$ observed for $1,2,3,7$, and 8 , describable as a localized $\pi-\pi *$ transition involving the phenacyl group. In the experimental absorption spectra, a large, weak, and broad peak was observable (Figure S3).

The greater extent of the conjugation in quinoline 3 determined an absorption at a longer wavelength with respect to the other compounds. Significant bands were observed up to about $350 \mathrm{~nm}$ and $380 \mathrm{~nm}$ for the samples in alcohols and chloroform, respectively, thereby showing a remarkable effect on the solvent. We suggested that this effect, not appreciable with the other quinolines, was caused by the aggregation of 3 in chloroform. The occurrence of $\pi$ stacking was particularly strong in quinoline 3 , in the view of the extended conjugation, and could stabilize these aggregates. However, it could not be excluded that the same phenomenon occurred in solutions of the other quinolines without a visible variation in the UV spectra. UV absorbance at a longer wavelength was confirmed in calculated spectra showing, only for 3, two intense bands in the range 300-400 nm (the band $0 \rightarrow 3$ and the band $0 \rightarrow 5$ which, from Table S1 and Figure S1, turned out to be CT transitions).

In order to qualitatively support the hypothesis of aggregation, we simulated the absorption spectrum of a dimer of quinoline 3 embedded into the chloroform meanfield effect. It was important to remark that more quantitative data would require a systematic analysis of the quinoline 3 aggregates, including species larger than dimers. However, the number and the relative orientation of the involved species made this analysis computationally intractable, and it was out of the scope of the present work.

For this reason, we only considered one optimized dimer, which we constructed only based on the idea of taking into account the possible $\pi$-stacking intermolecular interaction. The result, reported in Figure 3, indicated that the observed absorption pattern at lower energies was due to the presence of aggregation and also that it mainly referred to an electron-density transfer from $\mathrm{HOMO}$ delocalized over the two dimer partners to the more localized (either on the first or to the second partner) LUMO, LUMO + 1, and LUMO + 2 .

UV spectra collected for quinoline 3 , after loading into liposomes, clearly showed the longest wavelength band at an intermediate position in between those in alcohols and chloroform (Figure 4). This suggested the presence of quinoline aggregates after loading, reasonably with some distorted geometries compared to the one observed in chloroform. No changes were detected on the UV of the other quinolines upon loading in the lipid bilayer; this is shown, for example, for quinoline 7 in Figure S4.

As a whole, the experimental data and the theoretical calculations revealed sensitive effects of different substituents in modulating the electronic features of the investigated quinolines, thereby providing useful indications for a rational design of quinoline-based derivatives. Additional work is currently underway in our laboratory to extend the analysis to emission spectral features. 


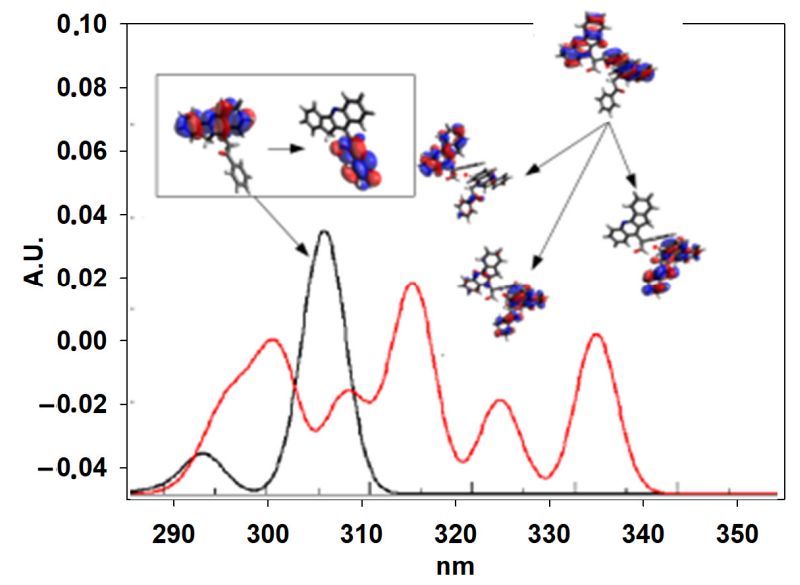

Figure 3. Comparison between the spectra of the monomer (black) and the dimer (red) of quinoline 3. The first three transitions for the dimer have been identified (from right to left) as $H \rightarrow L, H \rightarrow L+1$, and $\mathrm{H} \rightarrow \mathrm{L}+2$, respectively. Intensities correspond to oscillator strengths and must be considered as reported in arbitrary units.

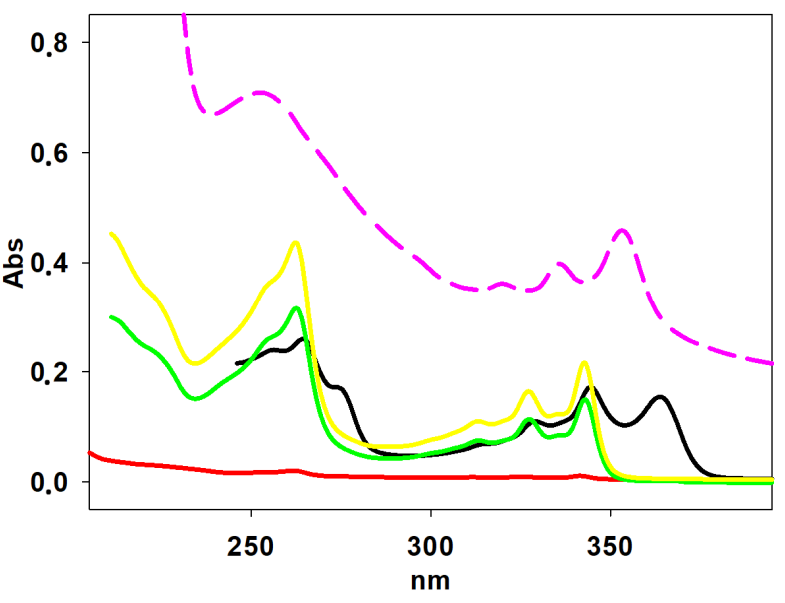

Figure 4. UV spectra of quinoline 3 in $n$-hexane (red line), chloroform (black line), methanol (yellow line), and 2-propanol (green line), and embedded in DMPC liposomes (dotted pink line).

\subsection{Liposomes Properties}

The rigidity and the organization of the bilayer can be crucial for the interactions of liposomes with the biological environment. In fact, the influence of the chemical structure of the lipids that composed the bilayer was relevant and might determine the biological fate of liposomes when employed as a drug delivery system. Based on these premises, we included each of the eight quinolines reported in this work into liposomes composed of either naturally saturated phospholipid of different chain length (DMPC or DPPC) or unsaturated ones (DOPC), in order to evaluate how and to what extent the mutual interaction solute/lipid could affect the overall properties of the aggregates.

In all cases, a very high E.E. (higher than 90 molar percentage) was observed independently of the chemical structures of the quinoline or the phospholipid. Considering the scarce solubility of the solute in water, this result was not surprising even with the high lipid/quinoline ratio (20/1) used in this investigation. The results suggested that quinolines were well accommodated in lipid bilayers both for their hydrophobicity and their molecular structure. Reasonably, the roughly planar geometry of these molecules easily fitted inside the bilayers with minimum distortions of the lipid packing. These findings were promisingly envisaging the use of liposomes as quinoline delivery systems. 
The effect of the inclusion of each quinoline into liposomes, analyzed in terms of aggregate size distributions, was investigated by DLS measurements on liposomes devoid or loaded with each quinoline (Figures 5 and 6, respectively).

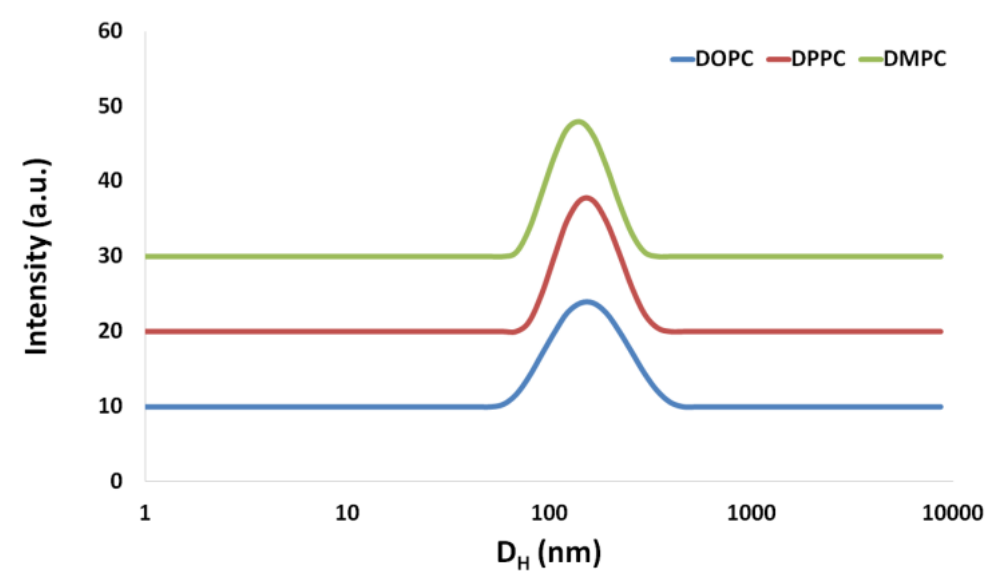

Figure 5. Hydrodynamic diameter $\left(\mathrm{D}_{\mathrm{H}}\right)$ intensity weighted distribution obtained by DLS on the free liposomes just after the preparation.
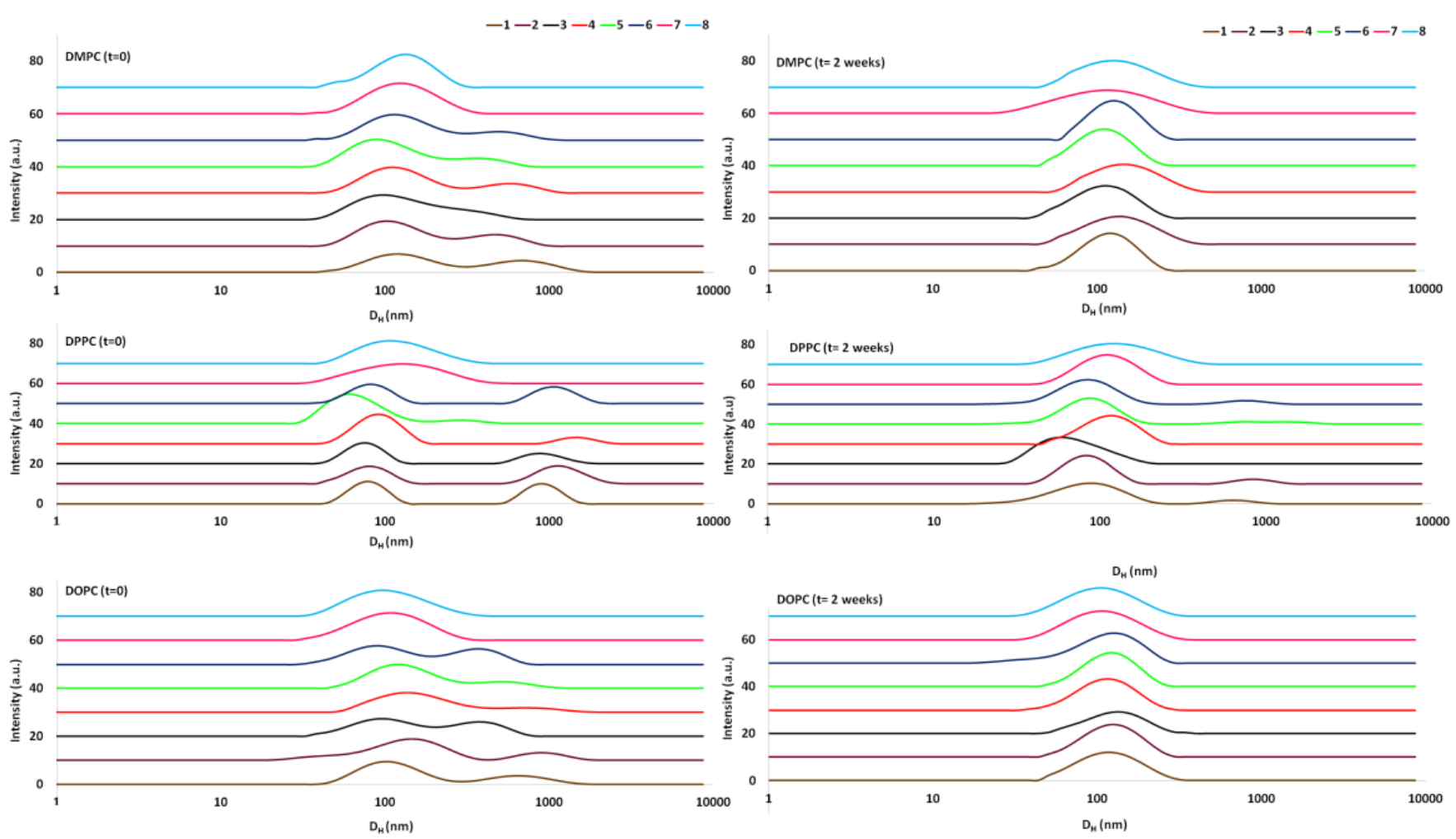

Figure 6. Intensity weighted distributions of the hydrodynamic diameter $\left(\mathrm{D}_{\mathrm{H}}\right)$ obtained by DLS on the quinoline loaded liposomes just after the preparation $(t=0)$ and after two weeks $(t=2$ weeks).

Monomodal distributions were obtained for cargo-free liposomes (Figure 5) with no relevant changes in time. By contrast, it can be clearly observed that, just after the preparation, liposomes containing non-steroidal quinolines showed a bimodal distribution with a major population at $D_{H}$ in the range $100-160 \mathrm{~nm}$ and a second population at larger values (Figure 6 and Table S3). SEM measurements confirmed the presence of liposomes and the range of the size detected by DLS (Figure S5). The populations at larger sizes tended to disappear over time, indicating that the investigated liposomes gradually rearranged 
and homogenized during storage. A reduction of aggregates dimensions upon storage could also be observed in the case of lipid vesicles prepared by other methodologies such as reverse phase evaporation $[49,50]$ or supercritical fluid technology [51,52]. For the freshly prepared samples, the population at larger sizes did not exceed $20 \%$ in the case of liposomes containing 4 or 5 , i.e., the smallest quinolines, independently of the chemical structure of the phospholipid. The larger relative amplitude of this population for 1, 2, 3, and 6 suggested that the presence of the phenacyl group in position 4 on the quinolines scaffold influenced lipid aggregation. In the case of DPPC liposomes, the population at a larger size was, in general, the most abundant (up to 50\%) and the most persistent for equal quinoline. DPPC liposomes were characterized by the most rigid and compact bilayer at room temperature; thus, it was not surprising that the lipid rearrangement took longer with respect to DOPC and DMPC liposomes. Interestingly, liposomes containing the steroidal quinolines $\mathbf{7}$ and $\mathbf{8}$ at the same molar ratio showed a single population at similar sizes for all the phospholipids that remained stable over two observation weeks. This result was unexpected since these quinolines, besides the phenacyl group, presented the bulky steroidal scaffold fused with the aromatic quinolines skeleton. Reasonably, the rigid steroidal portion of these molecules induced a different location of $\mathbf{7}$ and $\mathbf{8}$ in the lipid bilayer, with respect to the other investigated quinolines.

To better understand the effect of the quinolines on lipid packing and its dependence on the molecular structure of liposome components, we carried out DSC measurements. For these experiments, MLV were used in order to avoid complexity of the thermograms because of the fusion into larger aggregates during the scans observed for unilamellar vesicles [53]. The results of the SAXS measurements carried out on liposomes before sonication showed the multilamellar internal structure of the liposomal dispersions, which were composed of particles with an overall diameter larger than the maximum size accessible in the available reciprocal space range (>150 nm; Figure 7$)$. Well-defined diffraction peaks were seen as corresponding to characteristic spacings of the multilamellar structures of $6.61 \mathrm{~nm}, 6.41 \mathrm{~nm}$, and $6.38 \mathrm{~nm}$ for the DMPC, DOPC, and DPPC based formulations, respectively. In the DPPC case, third and fourth-order peaks were also detected in addition to the first two reflections. In addition, a broader peak contributed to the WAXS regime ( $q$ around 15-20 nm $\mathrm{nm}^{-1}$ ), corresponding to characteristic distances of the order of $0.4 \mathrm{~nm}$, and could be related to the lateral packing among the hydrophobic tails within the bilayers. The addition of quinolines to the formulations determined very slightly, not relevant changes in the width and position of the multilamellar peaks for the DMPC and DOPC samples, corresponding probably to a slight change of the average degree of multilamellarity (broadening) and spacing between the bilayers. A more pronounced modification could be observed in the case of the DPPC samples. In particular, for the quinoline 7, a remarkable broadening of the peaks could be detected, suggesting the presence of liposomes with a much lower number of stacked bilayers. In addition, in the low $\mathrm{q}$ region, a less negative initial slope could be observed, which indicated a smaller average size of the liposomes.

DSC thermograms allowed the identification of pretransition, when present, and main transition temperatures, $\mathrm{T}_{\mathrm{m}}$, of the lipid bilayers along with the corresponding enthalpy variation $\left(\Delta \mathrm{H}_{\mathrm{m}}\right)$ provided by the area of the transition peaks. In perfectly ordered bilayers, all the lipid molecules were expected to undergo the transition at the same temperature. In real samples, imperfect ordering of lipids, calorimetric lags, and finite scan rates determined a broadening of the peak due to transitions over finite ranges of temperature [54]. The width at half-height of the transition $\left(\Delta \mathrm{T}_{1 / 2}\right)$ and the shape of the peak also contained useful information on the system, and on the cooperativity of the transition. In fact, lipid packing could be affected by several factors such as the inclusion of solutes in the bilayer, presence of impurities, low miscibility of liposome components, or phase separations. All these aspects interfered with cooperative movements of lipids in the bilayer, with a consequent reduction of their interactions. This would be reflected in the thermal phase transition profile as a broadening of the peaks [55] and/or a lowering of their $\Delta \mathrm{H}_{\mathrm{m}}$ due to the increase in the available space between hydrophobic chains that led to an enhancement of their 
mobility. To evaluate the extent of variation of the lipid organization, the cooperative unit (CU) could be assessed. This parameter represented an estimation of the number of lipids undergoing the phase transition simultaneously (i.e., at the same temperature). $\mathrm{CU}$ can be obtained by the following equation

$$
\mathrm{CU}=\Delta \mathrm{H}_{\mathrm{vH}} / \Delta \mathrm{H}_{\mathrm{m}}
$$

where $\Delta \mathrm{H}_{\mathrm{vH}}$ indicates the van't Hoff enthalpy change, an estimate of the enthalpy associated to the transition that, based on the assumption of a simple two state first-order transition model, is given by

$$
\Delta \mathrm{H}_{\mathrm{vH}}=6.9 \mathrm{~J} / \mathrm{K}_{\operatorname{molT}_{\mathrm{m}}}{ }^{2} / \Delta \mathrm{T}_{1 / 2}
$$
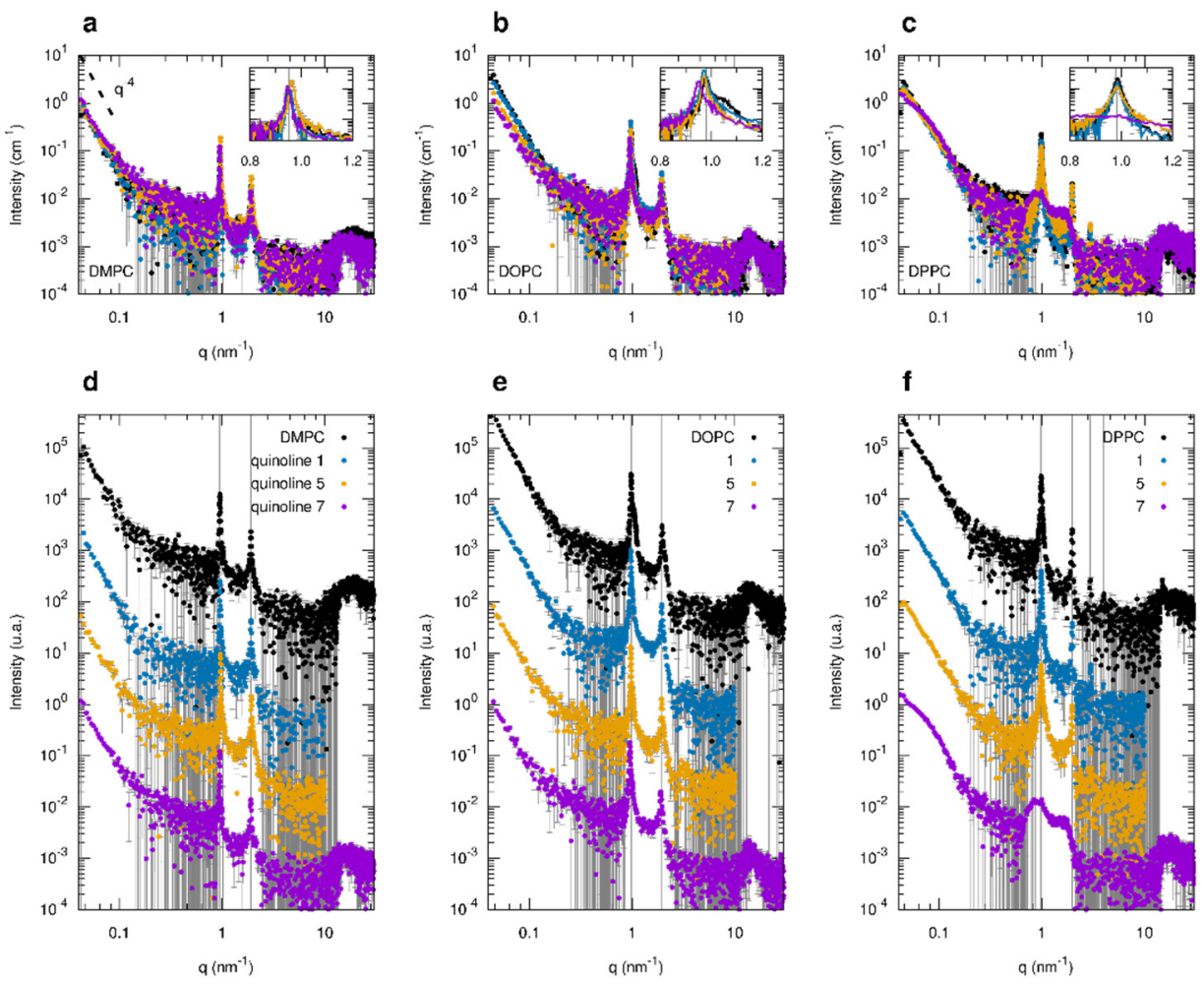

Figure 7. SAXS curves of free (black circles) and some quinoline-loaded phospholipid containing multilamellar vesicles (MLV; blue, orange, and purple circles for quinoline 1, 3, 5, respectively). In panels $(\mathbf{a}-\mathbf{c})$, the data for MLV containing DMPC, DOPC, and DPPC are shown, respectively, with intensity in absolute units. The insets highlight the first diffraction peak. In (d-f), the same curves have been shifted on the intensity axis by a suitable factor to avoid data overlap and help visualization.

In general, the lower the CU value, the higher the disorder of lipid molecules in the bilayer during the transition.

We observed that DSC thermograms (Figures 8-10) for both quinoline-loaded and empty liposomes presented show endothermic peaks. The profiles and the extracted parameters (Tables 1-3) showed differences that clearly confirmed the different interactions of the quinolines with the liposome bilayer upon loading. 


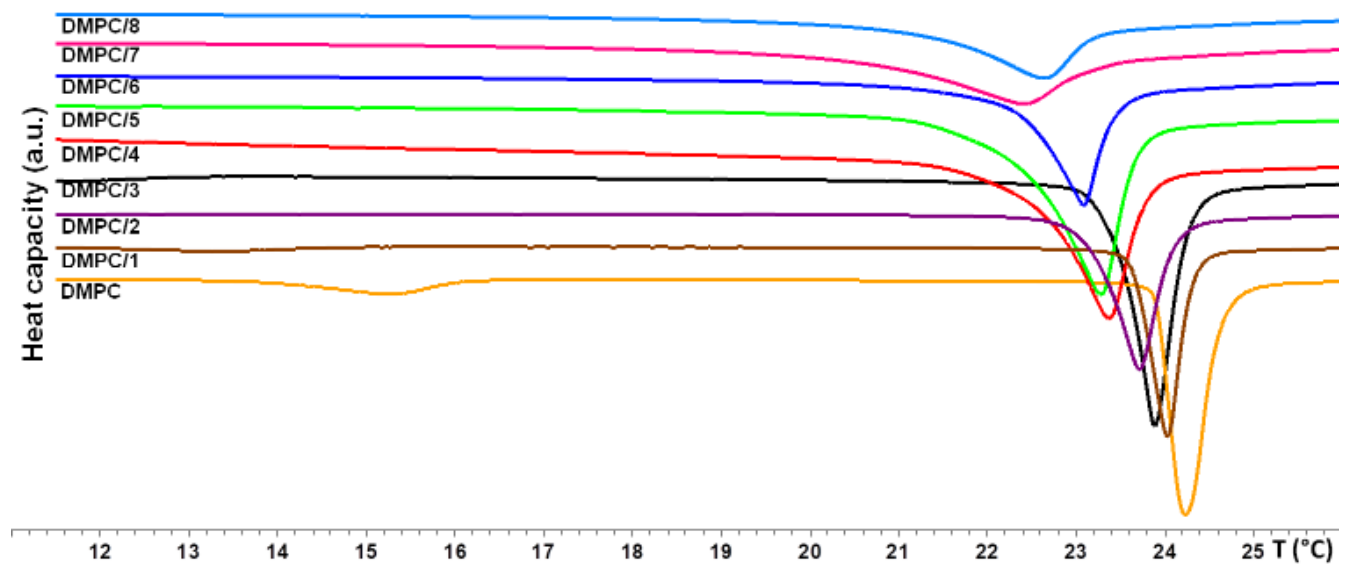

Figure 8. Thermograms of DMPC/quinolines MLV: DMPC, yellow line; DMPC/1, brown line; DMPC/2, purple line; $\mathrm{DMPC} / \mathbf{3}$, black line; $\mathrm{DMPC}$ 4, red line; $\mathrm{DMPC}$ 5, green line; DMPC/6, blue line; $\mathrm{DMPC} / \mathbf{7}$, pink line; DMPC/8, light blue line. Scan rate is $1^{\circ} \mathrm{C} / \mathrm{min}$.

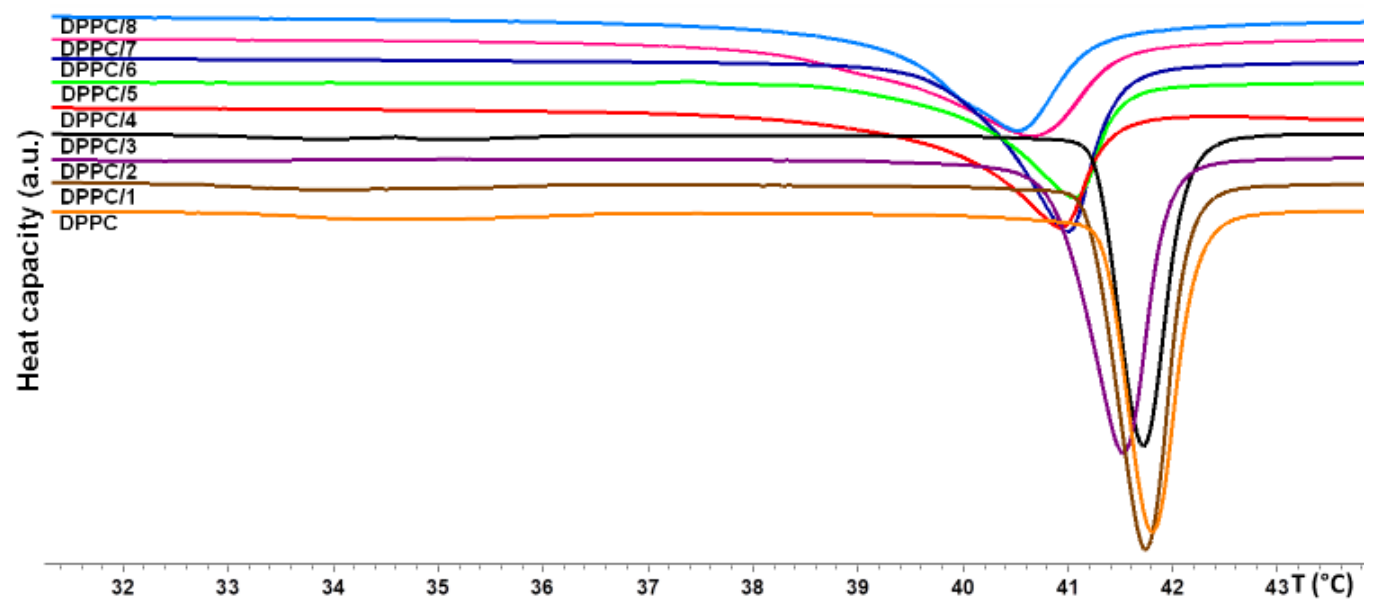

Figure 9. Thermograms of DPPC/quinolines MLV: DPPC, yellow line; DPPC/1, brown line; DPPC/2, purple line; DPPC/3, black line; DPPC /4, red line; DPPC/5, green line; DPPC/6, blue line; DPPC/7, pink line; DPPC/8, light blue line. Scan rate is $1^{\circ} \mathrm{C} / \mathrm{min}$.

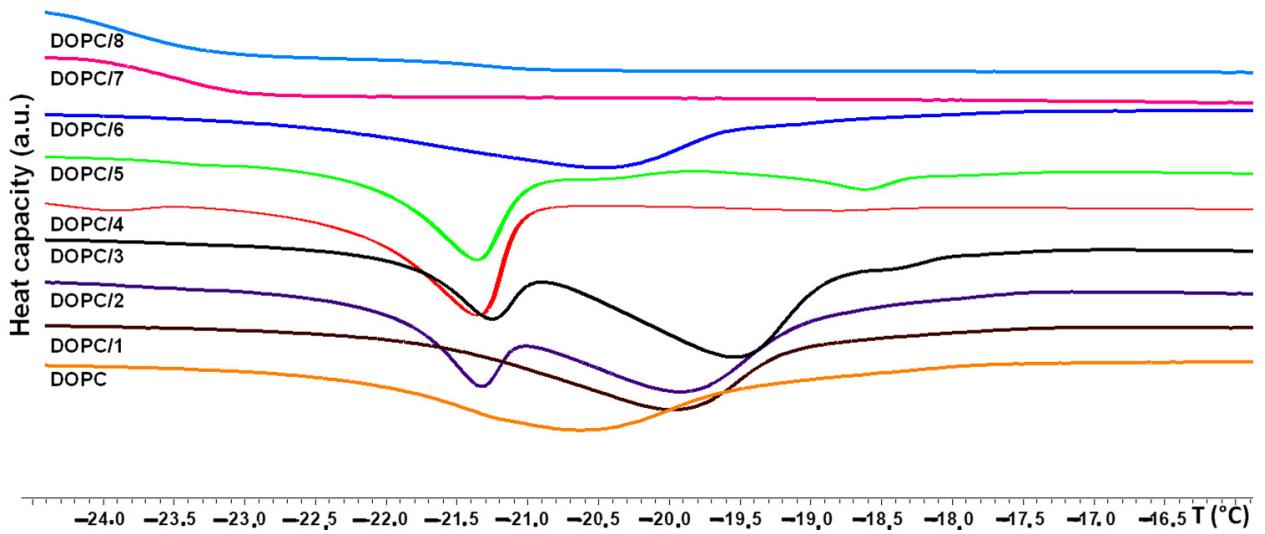

Figure 10. Thermograms of DOPC/quinolines MLV: DOPC, yellow line; DOPC/1, brown line; DOPC/2, purple line; $\mathrm{DOPC}$ /3, black line; DOPC /4, red line; DOPC/5, green line; DOPC/6, blue line; DOPC/7, pink line; DOPC/8, light blue line. Scan rate is $1^{\circ} \mathrm{C} / \mathrm{min}$. 
Table 1. Thermodynamic parameters obtained by DSC measurements on DMPC multilamellar vesicles with included quinolines 1-8. Uncertainties are $\pm 0.1^{\circ} \mathrm{C}$ in the temperatures and $\pm 0.5 \mathrm{~kJ} / \mathrm{mol}$ in the $\Delta \mathrm{H}_{\mathrm{m}}$ values.

\begin{tabular}{cccc}
\hline Formulation & $\mathbf{T}_{\mathbf{m}}\left({ }^{\circ} \mathbf{C}\right)$ & $\left.\Delta \mathbf{H}_{\mathbf{m}} \mathbf{( k J} / \mathbf{m o l}\right)$ & $\mathbf{C U}$ \\
\hline DMPC & 24.1 & 19.3 & 82 \\
DMPC + 1 & 24.0 & 18.6 & 81 \\
DMPC + 2 & 23.7 & 17.7 & 75 \\
DMPC + 3 & 23.9 & 16.9 & 77 \\
DMPC + 4 & 23.4 & 24.4 & 36 \\
DMPC + 5 & 23.3 & 28.0 & 45 \\
DMPC + 6 & 23.1 & 17.0 & 56 \\
DMPC + 7 & 22.4 & 17.0 & 22 \\
DMPC + 8 & 22.6 & 12.0 & 29 \\
\hline
\end{tabular}

Table 2. Thermodynamic parameters obtained by DSC measurements on DPPC multilamellar vesicles, including quinolines $\mathbf{1 - 8}$. Uncertainties are $\pm 0.1^{\circ} \mathrm{C}$ in temperatures and $\pm 0.5 \mathrm{~kJ} / \mathrm{mol}$ in $\Delta \mathrm{H}_{\mathrm{m}}$ values.

\begin{tabular}{cccc}
\hline Formulation & $\mathbf{T}_{\mathbf{m}}\left({ }^{\circ} \mathbf{C}\right)$ & $\left.\mathbf{\Delta H}_{\mathbf{m}} \mathbf{( k J / m o l}\right)$ & $\mathbf{C U}$ \\
\hline DPPC & 41.7 & 30.5 & 88 \\
DPPC + 1 & 41.6 & 36.2 & 74 \\
DPPC + 2 & 41.4 & 34.4 & 76 \\
DPPC + 3 & 41.6 & 35.6 & 78 \\
DPPC + 4 & 40.8 & 17.5 & 86 \\
DPPC + 5 & 41.0 & 18.6 & 80 \\
DPPC + 6 & 40.9 & 26.5 & 61 \\
DPPC + 7 & 40.6 & 22.4 & 44 \\
DPPC + 8 & 40.5 & 22.0 & 52 \\
\hline
\end{tabular}

Table 3. Thermodynamic parameters obtained by DSC measurements on DOPC multilamellar vesicles, including quinolines $1-8$. Uncertainties are $\pm 0.1^{\circ} \mathrm{C}$ in the temperatures and $\pm 0.5 \mathrm{~kJ} / \mathrm{mol}$ in the $\Delta \mathrm{H}_{\mathrm{m}}$ values.

\begin{tabular}{|c|c|c|c|}
\hline Formulation & $\mathrm{T}_{\mathrm{m}}\left({ }^{\circ} \mathrm{C}\right)$ & $\Delta \mathrm{H}_{\mathrm{m}}(\mathrm{kJ} / \mathrm{mol})$ & CU \\
\hline DOPC & -20.6 & 17.2 & 20 \\
\hline $\mathrm{DOPC}+1$ & -19.8 & 21.8 & 13 \\
\hline $\mathrm{DOPC}+2$ & $-19.8^{*}$ & 21.5 & - \\
\hline $\mathrm{DOPC}+3$ & $-19.6^{*}$ & 19.0 & - \\
\hline $\mathrm{DOPC}+4$ & -21.2 & 26.7 & 30 \\
\hline $\mathrm{DOPC}+5$ & -21.2 & 23.8 & 29 \\
\hline $\mathrm{DOPC}+6$ & -20.5 & 16.0 & 13 \\
\hline DOPC +7 & -22.8 & 7.6 & - \\
\hline DOPC + 8 & -23.0 & 7.9 & - \\
\hline
\end{tabular}

* second minor peak at $-21.3^{\circ} \mathrm{C}$.

In the case of DMPC liposomes, the interaction induced a systematic decrease in $\mathrm{T}_{\mathrm{m}}$ and a broadening of the peak, which was particularly marked for quinolines 4,7 , and 8 (Figure 10, Table 1). Similar results were observed upon the inclusion of other molecules in PC bilayers [56-58]. These pieces of evidence indicated that quinolines lowered the packing of the lipids, implying that they were located deeply into the hydrophobic region of the bilayer, as expected, considering their hydrophobic nature.

These effects were particularly marked with steroidal quinolines 7 and 8, suggesting that the high rigidity and the bulkiness of the steroidal scaffold sensitively reduced lipid packing and cooperativity of the transition. Accordingly, a remarkable lowering of the $\Delta \mathrm{H}_{\mathrm{m}}$ was observed, as well as of the associated CU value, reaching almost a quarter of the value recoded for free DMPC liposomes. It was also possible that 7 and $\mathbf{8}$ were located closer to the lipid headgroups with respect to the other quinolines because of their larger size 
and rigidity, which hindered their penetration into the bilayer. A different thermotropic behavior was observed when the other compounds, bearing the phenacyl group in position 4 , were included in the bilayer. Quinolines $\mathbf{1}-\mathbf{3}$ were probably located in the apolar region of the bilayer as well; however, the effect of these quinolines on the lipid packing was almost negligible as only a slight reduction of $\Delta \mathrm{H}_{\mathrm{m}}$ and of $\mathrm{CU}$ was observed. The apolar nature of these molecules most likely promoted hydrophobic interactions with the acyl chains of lipids with a reduced overall effect on lipid organization. A different behavior was shown by quinoline $\mathbf{6}$, which was very similar to quinoline 2 but was more polar because of two fluorine atoms and a methoxy group as substituents. Due to its higher polarity, 6 significantly disturbed the lipid packing when embedded in the apolar region of the bilayer, causing a reduction of the interactions among the lipid chains and, thereby, of $\mathrm{T}_{\mathrm{m}}$ and cooperativity of the transition [59]. Surprisingly, also quinolines 4 and 5 affected the lipid organization suggesting that thanks to their small dimensions and their low polarity, they could reach a deeper location in the bilayer, where the lipids were more tightly packed and, therefore, exert a more disturbing effect than the other quinolines. This hypothesis was supported by the evidence that the CU was halved with respect to free DMPC liposomes. On the other hand, an increase in the $\Delta \mathrm{H}_{\mathrm{m}}$ value was observed, pointing out that, because of their apolar nature, these quinolines were able to act as a hydrophobic glue deep in the interior of the bilayer, reinforcing the interactions among the lipid chains in the region where they were more tightly packed. An increase in $\Delta \mathrm{H}_{\mathrm{m}}$ in the presence of a solute due to its associating with bilayer interiors (with a consequent increase in van der Waals interactions) was also described in the literature [37,57].

Another common feature of formulations containing 4-8 was the asymmetry of the peak, which presented a tail at temperatures lower than $\mathrm{T}_{\mathrm{m}}$. This result indicated that quinolines 4-8 preferentially partitioned into the gel phase and thereby stabilized it. This behavior could be ascribed to different reasons depending on the quinoline scaffold. Probably, the extended linear structure of $\mathbf{7}$ and 8, in analogy with trans-parinaric acid [60], allowed them to co-crystallize with the rigid gel phase, whereas, in the case of 4 and 5 , the effect was due to stronger interactions in the gel phase with the methylenes of the acyl chains in a deeper region of the bilayer.

On replacing DMPC with DPPC liposomes, a similar trend was observed (Figure 9, Table 2). As a whole, liposomes, including 1-3, showed the most similar thermotropic behavior with respect to the empty liposomes whereas, the thermograms of liposomes, including $\mathbf{7}$ and $\mathbf{8}$, showed the most evident broadening of the peak and lowering of the $T_{m}$. Additionally, the asymmetry of the peaks of DPPC liposomes, including 4-8, and the effect of quinoline 6 was confirmed. Anyway, some relevant differences could be noticed, such as a slight decrease in $\mathrm{CU}$ and an increase in $\Delta \mathrm{H}_{\mathrm{m}}$ in the case of liposomes containing 1-3. This suggested that, in the rigid bilayer of DPPC liposomes with longer acyl chains, 1-3 established relevant interactions with lipids without disturbing their packing formulations. An inverse effect, i.e., a decrease in $\Delta \mathrm{H}_{\mathrm{m}}$ and an increase in $\mathrm{CU}$, together with a slight reduction of $T_{m}$, was observed in 4 and 5 . This evidence suggested that these apolar molecules, differing mostly in the dimensions, were located in the apolar region of the liposome bilayer but in a different position; thus, their effect on lipid organization differed in turn.

When the same quinolines were included in DOPC liposomes, thermograms of higher complexity were obtained (Figure 10, Table 3). Despite this, the lipid unsaturation made the bilayer more fluid, and the slackened presence of quinolines had a significant effect on the lipid organization as a function of the molecular structure. Quinolines 1-3 induced a slight shift of $\mathrm{T}_{\mathrm{m}}$ towards higher values and an increase in the corresponding $\Delta \mathrm{H}_{\mathrm{m}}$, indicating an attractive hydrophobic interaction with lipids that tended to make the bilayer more organized. In the case of $\mathbf{2}$ and $\mathbf{3}$, a minor second peak at a lower temperature appeared in the thermograms, indicating that the quinolines, partitioned in two regions of the bilayers, provided two different transitions. The presence of this second peak could also indicate the formation of a ripple gel phase, thus corresponding to the pre-transition. The peak at 
high temperature disappeared for the liposomes loaded with quinolines 4 and 5 , for which the largest increase in $\Delta \mathrm{H}_{\mathrm{m}}$ was observed. This result confirmed the specific behavior of 4 and $\mathbf{5}$ due to their ability to be tightly embedded into the bilayer due to their small dimensions and apolar nature. The disturbing effect of 6,7 , and 8 on the lipid packing was also confirmed by a significant reduction of $\Delta \mathrm{H}_{\mathrm{m}}$ and of $\mathrm{T}_{\mathrm{m}}$, the effect of $\mathbf{7}$ and 8 being particularly relevant as indicated by the remarkable broadening of the peak and reduction of $\mathrm{T}_{\mathrm{m}}$.

As a whole, the DSC results indicated that there was a complex interplay between the chemical structure of the lipid and the quinolines. The rigidity, polarity, and bulkiness of the quinolone molecule could severely affect the liposome properties and, in turn, their pharmacological activity.

\section{Conclusions}

The bioavailability of poorly water-soluble drugs like hydrophobic quinolines could be improved by loading them into liposomal carriers. Liposomes were largely investigated and used in drug delivery systems because of their ability to deliver hydrophobic and/or hydrophilic drugs, protecting them and reducing their toxicity while improving their pharmacokinetics [61]. The choice of the lipid components was crucial for determining the biological fate of the active molecule embedded in the bilayer of the carrier. The success of the delivery system had to be properly designed, depending on the physical characteristics of the drug. Here, quinolines with significantly different molecular scaffolds were included in liposomes composed of different phospholipids (DMPC, DPPC, and DOPC), with very high efficiency independently of the molecular structures. By contrast, effects on lipid packing and aggregation, sensitively dependent on quinoline and/or phospholipid molecular structures, were highlighted by calorimetry measurements upon loading. We also demonstrated that the UV absorption of quinolines was insensitive to the environment polarity unless they presented a significant expansion of the conjugation. Theoretical calculations suggested that staking interactions could be responsible for this behavior, which was expected to occur also upon inclusion into the liposome bilayer.

Supplementary Materials: The following are available online at https:/ /www.mdpi.com/article/10 .3390 / colloids5020028/s1, Coordinates of the quinolines optimized structures, Figures S1 and S2: Molecular orbitals of quinolines involved in the transitions, Figure S3: UV of quinolines at high concentrations, Figure S4: UV spectra of quinoline 7 in DMPC liposomes and in different solvents, Figure S5: SEM images of $1 \mathrm{mM}$ DMPC/ 2 sonicated liposomes, Table S1: main electronic transitions of quinolones, Table S2: transition energies of quinolines, Table S2: transition energies (eV) and oscillator strengths for the first twenty transitions of quinolines, Table S3: diameters and widths of the main peaks with the corresponding intensity weight inferred from the $\mathrm{D}_{\mathrm{H}}$ intensity weighted distributions.

Author Contributions: The manuscript was written with contributions of all authors. All authors have read and agreed to the published version of the manuscript.

Funding: This research was funded by the Sapienza University of Rome (RM11816428917C3F).

Data Availability Statement: Supporting data presented in this study are available in supplementary material here.

Acknowledgments: The authors acknowledge the CINECA (Italy) dor an Iscra-C grant and the use of the Gaussian 09 program. The authors thank Lorenzo Arrizza, Center of Microscopy of the University of L'Aquila, Italy, for his help on SEM observations.

Conflicts of Interest: The authors declare no conflict of interest. 


\section{References}

1. Marella, A.; Tanwar, O.P.; Saha, R.; Ali, M.R.; Srivastava, S.; Akhter, M.; Shaquiquzzaman, M.; Alam, M.M. Quinoline: A versatile heterocyclic. Saudi Pharm. J. 2013, 21, 1-12. [CrossRef]

2. Rehan, M.; Hazra, G.; Ghorai, P. Synthesis of Polysubstituted Quinolines via Transition-Metal-Free Oxidative Cycloisomerization of o-Cinnamylanilines. Org. Lett. 2015, 17, 1668-1671. [CrossRef]

3. Hall, D.G. Amines: Synthesis, Properties and Applications by Stephen, A. Lawrence (Mimas Ltd.). J. Am. Chem. Soc. 2005, 127, 9655-9658. [CrossRef]

4. Höglund, I.P.J.; Silver, S.; Engström, M.T.; Salo, H.; Tauber, A.; Kyyrönen, H.-K.; Saarenketo, P.; Hoffrén, A.-M.; Kokko, K.; Pohjanoksa, K.; et al. Structure-Activity Relationship of Quinoline Derivatives as Potent and Selective $\alpha 2 \mathrm{C}$-Adrenoceptor Antagonists. J. Med. Chem. 2006, 49, 6351-6363. [CrossRef] [PubMed]

5. Klingenstein, R.; Melnyk, P.; Leliveld, R.; Ryckebusch, A.; Korth, C. Similar Structure-Activity Relationships of Quinoline Derivatives for Antiprion and Antimalarial Effects. J. Med. Chem. 2006, 49, 5300-5308. [CrossRef]

6. Ma, X.; Zhou, W.; Brun, R. Synthesis, in vitro antitrypanosomal and antibacterial activity of phenoxy, phenylthio or benzyloxy substituted quinolones. Bioorg. Med. Chem. Lett. 2009, 19, 986-989. [CrossRef] [PubMed]

7. Kumar, S.; Bawa, S.; Drabu, S.; Panda, B.P. Design and synthesis of 2-chloroquinoline derivatives as non-azoles antimycotic agents. Med. Chem. Res. 2011, 20, 1340-1348. [CrossRef]

8. Raynes, K.; Foley, M.; Tilley, L.; Deady, L.W. Novel bisquinoline antimalarials: Synthesis, antimalarial activity and inhibition of haem polymerisation. Biochem. Pharmacol. 1996, 52, 551-559. [CrossRef]

9. Gomtsyan, A.; Bayburt, E.K.; Schmidt, R.G.; Zheng, G.Z.; Perner, P.J.; Didomenico, S.; Koenig, J.R.; Turner, S.; Jinkerson, T.; Drizin, I.; et al. Noveltransient receptor potential vanilloid 1 receptor antagonists for the treatment of pain: Structure-activity relationships for ureas with quinoline, isoquinoline, quinazoline, phthalazine, quinoxaline, and cinnoline moieties. J. Med. Chem. 2005, 48, 744-752. [CrossRef] [PubMed]

10. Ghosh, J.; Swarup, V.; Saxena, A.; Das, S.; Hazra, A.; Paira, P.; Banerjee, S.; Mondal, N.B.; Basu, A. Therapeutic effect of a novel anilidoquinoline derivative, 2-(2-methyl-quinoline-4ylamino)-N-(2-chlorophenyl)-acetamide, in Japanese encephalitis: Correlation with in vitro neuroprotection. Int. J. Antimicrob. Agents 2008, 32, 349-354. [CrossRef] [PubMed]

11. Scott, D.A.; Balliet, C.L.; Cook, D.J.; Davies, A.M.; Gero, T.W.; Omer, C.A.; Poondru, S.; Theoclitou, M.E.; Tyurin, B.; Zinda, M.J. Identification of 3-amido-4-anilinoquinolines as potent and selective inhibitors of CSF-1R kinase. Bioorg. Med. Chem. Lett. 2009, 19, 697-700. [CrossRef] [PubMed]

12. Baba, A.; Kawamura, N.; Makino, H.; Ohta, Y.; Taketomi, S.; Sohda, T. Studies on Disease-Modifying Antirheumatic Drugs: Synthesis of Novel Quinoline and Quinazoline Derivatives and Their Anti-inflammatory Effect1. J. Med. Chem. 1996, 39, 5176-5182. [CrossRef] [PubMed]

13. Smith, P.W.; Wyman, P.A.; Lovell, P.; Goodacre, C.; Serafinowska, H.T.; Vong, A.; Harrington, F.; Flynn, S.; Bradley, D.M.; Porter, R.; et al. New quinoline NK3 receptor antagonists with CNS activity. Bioorg. Med. Chem. Lett. 2009, 19, 837-840. [CrossRef]

14. Yan, R.; Liu, X.; Pan, C.; Zhou, X.; Li, X.; Kang, X.; Huang, G. Aerobic Synthesis of Substituted Quinoline from Aldehyde and Aniline: Copper-Catalyzed Intermolecular C-H Active and C-C Formative Cyclization. Org. Lett. 2013, 15, 4876-4879. [CrossRef]

15. Chung, P.Y.; Bian, Z.X.; Pun, H.Y.; Chan, D.; Chan, A.S.C.; Chui, C.H.; Tang, J.C.; Lam, K.H. Recent advances in research of natural and synthetic bioactive quinolines. Futur. Med. Chem. 2015, 7, 947-967. [CrossRef] [PubMed]

16. Zhang, J.; Yang, P.L.; Gray, N.S. Targeting cancer with small molecule kinase inhibitors. Nat. Rev. Cancer 2009, 9, 28-39. [CrossRef] [PubMed]

17. Dhanapal, R.; Perumal, P.T.; Damodiran, M.; Ramprasath, C. Synthesis of Quinoline Derivatives for Fluorescent Imaging Certain Bacteria. Bioorg. Med. Chem. Lett. 2012, 22, 6494-6497. [CrossRef] [PubMed]

18. Alam, R.; Mistri, T.; Katarkar, A.; Chaudhuri, K.; Kumar Mandal, S.; Khuda-Bukhsh, A.R.; Das, K.K.; Ali, M. A novel chromoand fluorogenic dual sensor for $\mathrm{Mg}^{2+}$ and $\mathrm{Zn}^{2+}$ with cell imaging possibilities and DFT studies. Analyst 2014, 139, 4022-4030. [CrossRef] [PubMed]

19. Qin, J.C.; Yang, Z.Y.; Fan, L.; Wang, B.D. $\beta$-Hydroxy- $\alpha$-naphthaldehyde [2-(quinolin-8'-yloxy) acetyl] hydrazone as an efficient fluorescent chemosensor for $\mathrm{Mg}^{2+}$. Spectrochim. Acta A Mol. Biomol. Spectrosc. 2015, 140, 21-26. [CrossRef]

20. Bordunov, A.V.; Bradshaw, J.S.; Zhang, X.X.; Dalley, N.K.; Kou, X.; Reed, M.I. Synthesis and Properties of 5-Chloro-8hydroxyquinoline-Substituted Azacrown Ethers: A New Family of Highly Metal Ion-Selective Lariat Ethers. Inorg. Chem. 1996, 35, 7229-7240. [CrossRef] [PubMed]

21. Farruggia, G.; Iotti, S.; Prodi, L.; Montalti, M.; Zaccheroni, N.; Savage, P.B.; Trapani, V.; Sale, P.; Wolf, F.I. 8-Hydroxyquinoline Derivatives as Fluorescent Sensors for Magnesium in Living Cells. J. Am. Chem. Soc. 2006, 128, 344-350. [CrossRef]

22. Katritzky, A.R.; Rees, C.W.; Scriven, E.F.V. Comprehensive Heterocyclic Chemistry II, 1st ed.; Pergamon Press: Oxford, UK, 1996; pp. 245-300.

23. Jaromin, A.; Kozubek, A.; Suchoszek-Lukaniuk, K.; Malicka-Blaszkiewicz, M.; Peczynska-Czoch, W.; Kaczmarek, L. Liposomal Formulation of DIMIQ, Potential Antitumor Indolo[2,3-b]Quinoline Agent and Its Cytotoxicity on Hepatoma Morris 5123 Cells. Drug Deliv. 2008, 15, 49-56. [CrossRef] [PubMed]

24. "Quinoline", Encyclopædia Britannica, 11th ed.; Cambridge University Press: Cambridge, UK, 1922; p. 759.

25. Koning, G.A.; Storm, G. Targeted drug delivery systems for the intracellular delivery of macromolecular drugs. Drug Discov. Today 2003, 8, 482-483. [CrossRef] 
26. Metselaar, J.M.; Storm, G. Liposomes in the treatment of inflammatory disorders. Expert Opin. Drug Deliv. 2005, 2, 465-476. [CrossRef] [PubMed]

27. Ding, B.S.; Dziubla, T.; Shuvaev, V.V.; Muro, S.; Muzykantov, V.R. Advanced drug delivery systems that target the vascular endothelium. Mol. Interv. 2006, 6, 98-112. [CrossRef]

28. Hua, S.; Wu, S.Y. The use of lipid-based nanocarriers for targeted pain therapies. Front. Pharmacol. 2013, 4, 143. [CrossRef]

29. Akbarzadeh, A.; Rezaei-Sadabady, R.; Davaran, S.; Joo, S.W.; Zarghami, N.; Hanifehpour, Y.; Samiei, M.; Kouhi, M.; Nejati-Koshki, K. Liposome: Classification, preparation, and applications. Nanoscale Res. Lett. 2013, 8, 102. [CrossRef] [PubMed]

30. Sharma, A.; Mayhew, E.; Straubinger, R.M. Antitumor effect of taxol-containing liposomes in taxol resistant murine tumor model. Cancer Res. 1993, 53, 5877-5881.

31. Sharma, A.; Straubinger, R.M. Novel Taxol Formulations: Preparation and Characterization of Taxol-Containing Liposomes. Pharm. Res. 1994, 11, 889-896. [CrossRef]

32. Crosasso, P.; Ceruti, M.; Brusa, P.; Arpicco, S.; Cattel, L. Preparation, characterization and properties of sterically stabilized paclitaxel-containing liposomes. J. Control. Release 2000, 63, 19-30. [CrossRef]

33. Gogoi, S.; Shekarrao, K.; Duarah, A.; Bora, T.C.; Gogoi, S.; Boruah, R.C. A microwave promoted solvent-free approach to steroidal quinolines and their in vitro evaluation for antimicrobial activities. Steroids 2012, 77, 1438-1445. [CrossRef]

34. Yang, Y.T.; Du, S.; Wang, S.; Jia, X.; Wang, X.; Zhang, X. Synthesis of new steroidal quinolines with antitumor properties. Steroids 2019, 151, 108465. [CrossRef] [PubMed]

35. Shiro, T.; Fukaya, T.; Tobe, M. The chemistry and biological activity of heterocycle-fused quinolinone derivatives: A review. Eur. J. Med. Chem. 2015, 97, 397-408. [CrossRef] [PubMed]

36. Battista, S.; Campitelli, P.; Galantini, L.; Köber, M.; Vargas-Nadal, G.; Ventosa, N.; Giansanti, L. Use of N-oxide and Cationic Surfactants to Enhance Antioxidant Properties of (+)-Usnic Acid Loaded Liposomes. Colloids Surfaces A 2019, 585, 124154. [CrossRef]

37. Battista, S.; Maggi, M.A.; Bellio, P.; Galantini, L.; D'Archivio, A.A.; Celenza, G.; Colaiezzi, R.; Giansanti, L. Curcuminoids-loaded Liposomes: Influence of Lipid Composition on Their Physicochemical Properties and Efficacy as Delivery Systems. Colloids Surfaces A 2020, 597, 124759. [CrossRef]

38. Battista, S.; Bellio, P.; Celenza, G.; Galantini, L.; Franceschini, I.; Mancini, G.; Giansanti, L. Correlation of Physicochemical and Antimicrobial Properties of Liposomes Loaded with (+)-Usnic Acid. ChemPlusChem 2020, 85, 1014-1021. [CrossRef]

39. Marsicano, V.; Chiarini, M.; Marinelli, F.; Arcadi, A. Synthesis of Polycyclic Quinolines by Means of Brønsted Acid Mediated Reaction of $\beta$-(2-Aminophenyl)- $\alpha, \beta-Y$ nones with Ketones. Adv. Synth. Catal. 2019, 361, 2365-2370. [CrossRef]

40. Arcadi, A.; Chiarini, M.; Di Giuseppe, S.; Marinelli, F. A New Green Approach to the Friedländer Synthesis of Quinolines. Synlett 2003, 2, 203-206. [CrossRef]

41. Becke, A.D. A new mixing of Hartree-Fock and local density-functional theories. J. Chem. Phys. 1993, 98, 5648-5652. [CrossRef]

42. Lee, C.; Yang, W.; Parr, R.G. Development of the Colle-Salvetti correlation-energy formula into a functional of the electron density. Phys. Rev. B 1988, 37, 785-789. [CrossRef] [PubMed]

43. Runge, E.; Gross, E.K.U. Density-Functional Theory for Time-Dependent Systems. Phys. Rev. Lett. 1984, 52, 997-1000. [CrossRef]

44. Tomasi, J.; Mennucci, B.; Cammi, R. Quantum Mechanical Continuum Solvation Models. Chem. Rev. 2005, 105, 2999-3094. [CrossRef] [PubMed]

45. Frisch, M.J.; Trucks, G.W.; Schlegel, H.B.; Scuseria, G.E.; Robb, M.A.; Cheeseman, J.R.; Scalmani, G.; Barone, V.; Petersson, G.A.; Nakatsuji, H.; et al. Gaussian 09, Revision A.02; Gaussian, Inc.: Wallingford, UK, 2016.

46. Sztucki, M.; Narayanan, T. Development of an ultra-small-angle X-ray scattering instrument for probing the microstructure and the dynamics of soft matter. J. Appl. Crystallogr. 2007, 40, s459-s462. [CrossRef]

47. Pounraj, P.; Mohankumar, V.; Senthil Pandian, M.; Ramasamy, P. Donor functionalized quinoline based organic sensitizers for dyesensitized solar cell (DSSC) applications: DFT and TD-DFT investigation. J. Mol. Model. 2018, 24, 343-366. [CrossRef]

48. Fazal, E.; Jasinski, J.P.; Anderson, B.J.; Kaur, M.; Nagarajan, S.; Sudha, B.S. Synthesis, Crystal and Molecular Structure Studies and DFT Calculations of Phenyl Quinoline-2-Carboxylate and 2-Methoxyphenyl Quinoline-2-Carboxylate: Two New Quinoline-2 Carboxylic Derivatives. Crystals 2015, 5, 100-115. [CrossRef]

49. Hathout, R.M.; Mansour, S.; Mortada, N.D.; Guinedi, A.S. Liposomes as an Ocular Delivery System for Acetazolamide: In Vitro and In Vivo Studies. AAPS PharmSciTech 2007, 8, E1-E12. [CrossRef]

50. Ma, Q.H.; Hao, X.Z.; Zhou, H.F.; Gu, N. Effect of Surfactants on Preparation and Skin Penetration of Tea Polyphenols Liposomes. In Proceedings of the IEEE/ICME International Conference on Complex Medical Engineering, Beijing, China, 23-27 May 2007; pp. 209-212.

51. Santo, I.E.; Campardelli, R.; Albuquerque, E.C.; de Melo, S.V.; Della Porta, G.; Reverchon, E. Liposomes preparation using a supercritical fluid assisted continuous process. Chem. Eng. J. 2014, 249, 153-159. [CrossRef]

52. Otake, K.; Shimomura, T.; Goto, T.; Imura, T.; Furuya, T.; Yoda, S.; Takebayashi, Y.; Sakai, H.; Abe, M. Preparation of Liposomes Using an Improved Supercritical Reverse Phase Evaporation Method. Langmuir 2006, 22, 2543-2550. [CrossRef]

53. Drazenovic, J.; Wang, H.; Roth, K.; Zhang, J.; Ahmed, S.; Chen, Y.; Bothun, G.; Wunder, S.L. Effect of lamellarity and size on calorimetric phase transitions in single component phosphatidylcholine vesicles. Biochim. Biophys. Acta 2015, 1848, 532-543. [CrossRef] 
54. Sturtevant, J.M. A scanning calorimetric study of small molecule-lipid bilayer mixtures. Prot. Natl. Acad. Sci. USA 1982, 79, 3963-3967. [CrossRef]

55. Castile, J.D.; Taylor, K.M.G.; Buckton, G. A high sensitivity differential scanning calorimetry study of the interaction between poloxamers and dimyristoylphosphatidylcholine and dipalmitoylphosphatidylcholine liposomes. Int. J. Pharm. 1999, 182, 101-110. [CrossRef]

56. Bakonyi, M.; Berko', S.; Budai-Szücs, M.; Kovács, A.; Csányi, E. DSC for evaluating the encapsulation efficiency of lidocaine loaded liposomes compared to the ultracentrifugation method. J. Therm. Anal. Calorim. 2017, 130, 1619-1625. [CrossRef]

57. Ali, S.; Minchey, S.; Janoff, A.; Mayhew, E. A Differential Scanning Calorimetry Study of Phosphocholines Mixed with Paclitaxel and Its Bromoacylated Taxanes. Biophys. J. 2000, 78, 246-256. [CrossRef]

58. Di Foggia, M.; Bonora, S.; Tinti, A.; Tugnoli, V. DSC and Raman study of DMPC liposomes in presence of Ibuprofen at different pH. J. Therm. Anal. Calorim. 2017, 127, 1407-1417. [CrossRef]

59. Biltonen, R.L.; Lichtenberg, D. The use of differential scanning calorimetry as a tool to characterize liposome preparations. Chem. Phys. Lipids 1993, 64, 129-142. [CrossRef]

60. Sklar, L.A.; Miljanich, G.P.; Dratz, E.A. Phospholipid Lateral Phase Separation and the Partition of Cis-Parinaric Acid and Trans-Parinaric Acid Among Aqueous, Solid Lipid, and Fluid Lipid Phases. Biochemistry 1979, 18, 1707-1716. [CrossRef] [PubMed]

61. Jain, S.; Jain, V.; Mahajan, S.C. Lipid Based Vesicular Drug Delivery Systems. Adv. Pharm. 2014. [CrossRef] 